\title{
Organizational Change In Small And Medium Size Enterprises: Practice, Frequency And Achievement Of Objectives
}

Heather Banham, Ph.D., Okanagan College, Canada Yunke He, Ph.D., Okanagan College, Canada

\begin{abstract}
Organizational changes are experienced by $40 \%$ of a group of Small and Medium Enterprises (SMEs) in Canada according to authors' recent survey. These SMEs report substantive attainment of the objectives which were pursued in implementing these change practices. An emerging concern in the pursuit and attainment of greater labour flexibility as an objective is that it impairs the creation of full time employment opportunities which is one of the expectations for SMEs. Data analysis fails to provide evidence of a strong link between implementation of organizational changes and financial performance of these firms, of which $80 \%$ have been operating for more than five years.
\end{abstract}

Keywords: Organizational Change; Small and Medium Enterprises (SMEs), Practices; Objectives

\section{INTRODUCTION}

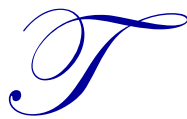

he increasing importance of SMEs is a global phenomenon brought about by market forces, technological advances, personal career aspirations and underlying demographic changes in the population. In the Organisation for Economic Cooperation and Development countries, SMEs account for 95 percent of the enterprises and 60 to 70 percent of the employment. In Canada, 99.7 percent of the business enterprises are classified as SME firms. They are vital to the Canadian economy from a number of perspectives, such as employment, innovation, exports and gross domestic product.

Despite the importance of SMEs to the economy and their resilience to economic downturns, there has been a shortage of data concerning the patterns and trends in organizational change practices in SMEs (Prater \& Ghosh, 2006). This article intends to contribute to filling in this research gap with an analysis of the adoption of organizational change practices in SMEs in Canada.

In examining best practice interventions in SMEs, Done, Voss and Rytter (2011) determine that resource limitations impeded the ability of SMEs to develop long term outcomes from these changes. In their study they included Total Quality Management (TQM), Just in Time (JIT), lean production, continuous improvement (Kaizen) and six sigma change processes in their definition of best practice interventions. The changes introduced delivered short-term improvements in the eight SMEs studied while only one of the SMEs demonstrated sustained, long term improvement.

Earlier research demonstrated the unique characteristics of SMEs (Banham, 2005) and more recently, flexibility and closeness to the market enabled small supplier firms in the United States to increase sales in the contracting housing market (Bubgardner, Buehlmann, Schuler, \& Crissey, 2011).

Successful change management is reported as essential for survival and success of SMEs in the tourism industry in the United Kingdom and eight critical success factors are identified (By \& Dale, 2008) for implementing organizational changes. Organizational change competencies are ranked highly by these SMEs yet they 
acknowledge no formal training in the area. Reactionary rather than planned changes are commonly reported yet fine-tuning, incremental adjustment, modular and complete corporate transformations are considered essential to long-run organizational development.

Further, the growing importance of SMEs to the transition economy in China and the potential application of human resource management (HRM) practices to these organizations is considered by Cunningham (2010) and there is some preliminary evidence to support the association of HRM practices with enterprise performance along with an emphasis on cultural factors such as the unanticipated increase in guangxi (networking) as influencers in HRM practices.

International business initiatives of SMEs are facilitated by the world-wide web and related technology and the new communication tools make globalization an attainable reality for these firms (Bell \& Loane, 2010). Engagement in international trade provides SMEs with expanded markets and supply lines.

Consultation, adoption and implementation of appropriate organizational change are required to meet the different needs of the four generations in the work place with appropriate HRM practices, and to develop new markets and supply lines through internationalization, flexible work practices to adjust to economic and business cycles.

The next section describes the research objectives addressed in this article.

\section{RESEARCH OBJECTIVE}

The following research questions (RQ) are formulated in relation to SMEs in Canada to consider organizational change practices and the objectives pursued in implementing those changes:

RQ1 What organizational change practices are being adopted in these SMEs?

RQ2 What objectives are pursued with the introduction of organizational changes in these SMEs?

RQ3 To what extent are the objectives achieved as a result of the introduction of organizational changes in these SMEs?

RQ4 Is there a significant relationship between capacity for organizational change and financial performance?

To explore the above research questions, primary data is collected using a survey questionnaire. The questionnaire is structured into two parts: demographic variables and organizational change practices. Both qualitative and quantitative methods will be used to analyze the data and the findings will be analyzed to address the research questions.

The design, development, approval, translation, circulation and communication of the survey questionnaire for this research project are described in the next section.

\section{METHODOLOGY}

The questionnaire was adapted to the Canadian environment, with permission, from a similar study undertaken in Australia ${ }^{1}$. The long form of the survey is structured in four parts: Demographic Variables, Business Planning, Human Resources Management, and Organizational Change practices. This analysis concentrates on two parts - the demographic variables and the organizational change practices. The research project including the survey form was approved by the institutional Research Ethics Board. The population for this study is all Canadian businesses employing between 20 and 200 employees and the calculations of sample size and response rates for statistical significance were incorporated into the research design. There is no control group in this study.

${ }^{1}$ Dr. Retha Wiesner, Associate Professor, Business, University of Southern Queensland 
The listing of all businesses in Canada employing between 20 and 200 employees was built from a commercial subscription and comprised over 7000 names. The calculation for a statistical significant response indicated 370 valid responses required. The survey is distributed in electronic format and accessed from the institutional website. The 370 valid responses were not received. Therefore a short form of the survey was developed comprising only the demographic section and the organizational change practices. While additional responses were received the target of 370 valid responses was still not attained. The smaller data set of 77 is used for exploratory purposes and is not considered to be statistically significant. It is analysed to explore any significant relationships.

This underlying data set for this research is comprised from 63 responses from the long form survey and 14 responses to the short form survey for a total of 77 responses. The short form responses are downloaded directly from the website from the responses provided by the SMEs, the additional 63 responses are entered from the responses to the relevant sections of the long form survey. An audit procedure is used to confirm accuracy of the data entry process. The audit procedure involves pre-selection of long form surveys numbered 15,30 and 45 for verification of data directly on the survey form to the spreadsheet, and checking four data points - A1 Number of Employees, A6 NAICS Classification, D2 Major Change in Product or Service, D4 Customer Expectations for Price. The three sets of data are confirmed on each of the 4 data points as $100 \%$ accurate.

This paper is developed from the demographic variables and the organizational change practices, objectives and attainment of the objectives sections.

\section{DATA ANALYSIS AND RESULTS}

Responses from 77 organizations comprise the data set. There are 31 questions about respondents themselves and their organizations in the survey. Selected information describing the profile of the respondent organizations is presented in Tables 1,2, and 3. It includes the size of participating organizations in terms of the number of employees, the sectors in which they operate, and their history measured by the number of years since establishment.

Table 1 - Number of Employees in Respondent SMEs

\begin{tabular}{|c|c|c|c|c|}
\hline Fewer than 20 & $\mathbf{2 1 - 5 0}$ & $\mathbf{5 1 - 1 0 0}$ & $\mathbf{1 0 1 - 2 0 0}$ & More than 200 \\
\hline 17 & 30 & 16 & 7 & 7 \\
\hline $22 \%$ & $39 \%$ & $21 \%$ & $9 \%$ & $9 \%$ \\
\hline
\end{tabular}

Table 1 data shows that more than $80 \%$ of surveyed organizations have 100 or fewer employees. Therefore the sample gives a good representation of SMEs despite the small sample size.

Table 2 - Industry Sector of Respondent SMEs

\begin{tabular}{|c|c|c|}
\hline $\begin{array}{c}\text { Primary } \\
\text { (Agriculture, Mining, etc.) }\end{array}$ & $\begin{array}{c}\text { Secondary } \\
\text { (Manufacturing) }\end{array}$ & $\begin{array}{c}\text { Tertiary } \\
\text { (Services and Professions) }\end{array}$ \\
\hline 4 & 20 & 53 \\
\hline $5 \%$ & $26 \%$ & $69 \%$ \\
\hline
\end{tabular}

Table 2 shows that nearly $70 \%$ of surveyed organizations are in the services and professions sector, which also confirms the business nature of the majority of SMEs. Therefore the survey sample is representative of the population in this regard.

Table 3 - Years since Establishment of Respondent SMEs

\begin{tabular}{|c|c|c|c|c|}
\hline Less than 1 year & $\mathbf{1 - 2}$ & $\mathbf{3 - 5}$ & $\mathbf{6 - 1 0}$ & More than 10 years \\
\hline 3 & 1 & 3 & 12 & 58 \\
\hline $4 \%$ & $1 \%$ & $4 \%$ & $16 \%$ & $75 \%$ \\
\hline
\end{tabular}

Table 3 shows that more than $90 \%$ of surveyed organizations have existed for more than 5 years, which justifies the validity of the survey results in terms of organizational change because these have been operating long enough to have solved any early working capital challenges and to establish their work force. 
Taken in combination, these three factors indicate the respondent SMEs predominantly have 100 or fewer employees, operate in the services/professions sector and have been operating for more than five years.

In addition, a question is asked about how respondents rate their firms' financial performance over the last three years. Five levels of financial performance are used to collect information. The percentages of firms of each financial performance level are summarized in Table 4.

Table 4 - Percentage of Firms at Each Financial Performance Level

\begin{tabular}{|c|c|c|c|c|}
\hline Substantial Loss & Moderate Loss & Basically Break-even & Moderate Profit & Substantial Profit \\
\hline $10 \%$ & $10 \%$ & $21 \%$ & $49 \%$ & $5 \%$ \\
\hline
\end{tabular}

Table 4 shows that about $20 \%$ of firms have incurred losses over the last three years, while nearly $50 \%$ of firms have made profits.

Three questions with multiple parts are asked in the survey related to organizational change. The answers to these three questions are used to examine the frequency of organizational changes, objectives pursued and level of success in attainment of those objectives.

\section{Question One: Which of the following practices have been applied in your organization in the past 3 years?}

1. Part-time work

2. Paid parental leave

3. Study leave and assistance

4. Job sharing

5. $\quad$ Flexible hours of work

6. Work arrangements allowing employees to 'purchase' extra leave

7. $\quad$ Planned days off or flex days

8. Telecommuting /or work from home

9. Career breaks (allowing employees to return to their job after break)

10. Casual work

11. Child care

12. Phased retirement options

13. Annualized hours

14. Compressed work week

15. Independent contractors

16. Dependent contractors

17. Contracting out work once performed by your employees

18. Job rotation

19. Job enrichment

20. Team building

21. Quality problem solving teams

22. Self-managing work teams

23. Productivity improvement schemes

24. Joint consultative committees

25. Total Quality Management

26. Benchmarking

27. Best Practice (comparing your organization with other similar organizations within Canada)

28. Best Practice (comparing your organization with other similar organizations internationally)

29. Re-engineering business practices/processes

30. Cross functional project teams

31. Quality programs (i.e. ISO9000)

32. Developing alliances with skill/product providers not available in-house

33. Use of external consultants in relation to change management issues

34. Workforce planning 
35. Succession planning for managers

36. Succession planning for the CEO

37. Environmental sustainability initiatives (green initiatives)

A graphical frequency distribution is shown in Figure 1. The horizontal axis denotes each practice from 1 to 37 ; the vertical axis denotes the number of organizations applying each practice.

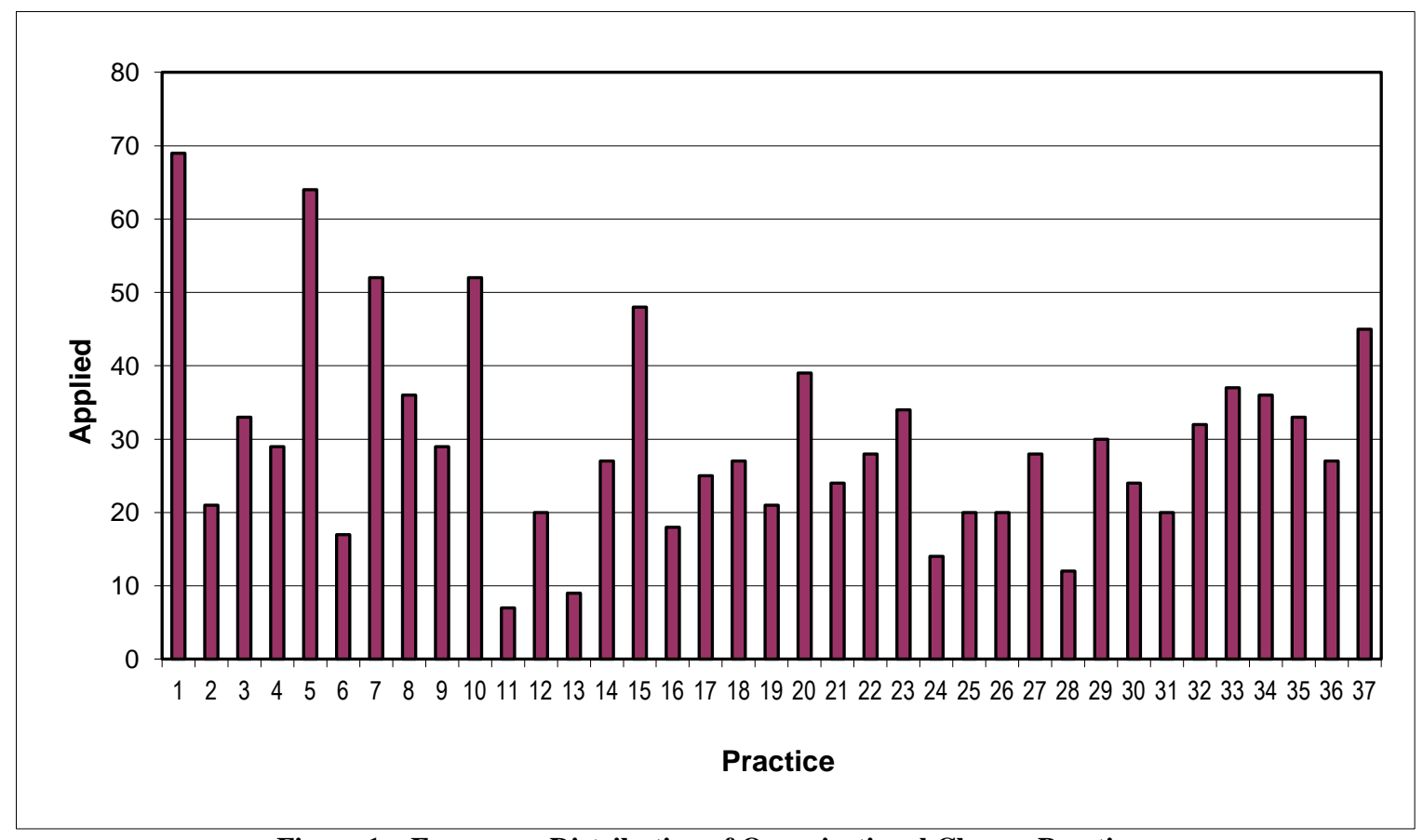

Figure 1 - Frequency Distribution of Organizational Change Practices

The summary statistics show that the average number of organizations applying these practices is 30 , which represents $40 \%$ of respondent organizations. The most applied practice is part-time work (number 1) with almost all firms reporting implementation of this practice, followed by flexible hours of work (number 5). Planned days off or flex days and casual work (numbers 7 and 10), and use of independent contractors (number 15) also indicate high levels of adoption. All of these frequently used changes are employment and work force related. These practices enable SMEs to adjust capacity to demand. However it also opens the possibility that the flexibility of SMEs is sometimes bought at the expense of full time jobs, which is one of the important contributions which SMEs are expected to make to their host economies. This is a question that warrants further research.

Practices such as study leave, job enrichment and job sharing are normally directed at increasing employee engagement and retention; and SMEs report moderate levels of participation in these practices. With the projected future impact of demographics on the availability of workers it will be essential for SMEs to be involved in these types of practices.

The least applied practice is the provision of child care (number 11), followed by annualized hours (number 13), best practice internationally (number 28), joint consultative committees between employer and employees for process and organizational enhancement (number 24), and work arrangements allowing employees to "purchase" extra leave (number 6). These least applied practices indicate these SMEs are not maximizing the opportunity to learn from employees and from other organizations, nor are they implementing some of the proven retention practices to keep their employees.

It is interesting to note the level of engagement in green initiatives (number 37) as increased awareness of sustainability occurs throughout the business environment. SMEs by their nature have the opportunity to be closely tuned to such changes. 
No attempt is made to quantify the 37 practices in terms of the importance of each practice to successful organizational change, as each practice is potentially influenced by various factors such as the nature of the organizations, their geographic locations, and the organizational culture. For this next analysis and in the interests of simplicity and practicality, an equal weight is assigned to each practice. First, the numbers of the practices applied by each organization have been counted. Then we examine the relationship between the number of practices applied and the level of financial performance (the profit or loss level), which is also collected in the survey. This is accomplished by calculating the correlation coefficient between these two variables. The result shows a coefficient of -0.07257 , which is statistically insignificant. Therefore the number of organizational change practices has no relationship with the profit or loss level.

The result should not be a surprise for at least two reasons. Firstly, the purpose in applying these practices in organizational change is not solely for the improvement of financial performance. Examples are part-time work, paid parental leave, and provision of child care. Secondly, applying some of these practices requires a significant financial commitment in the short or intermediate term; and the positive effects of the practices applied in an organization will take time to be reflected in financial outcome. Some examples of this are study leave and assistance, job enrichment, and re-engineering business practices and processes.

\section{Question Two: Which of the following changes have occurred in your organization in the past three years?}

1. Major change in product or service

2. Major restructuring of how work is done

3. New ownership of the organization

4. Reorganization of management structure

5. Change in management personnel

6. Major new plant, equipment or technology

7. Changes to the structure of the workforce

8. Process change

9. Systems change

10. Organizational structure change

11. Change in job roles of employees

12. Staff reduction (in managers)

13. Staff reduction (in employees)

14. Significantly increased production levels

15. Open new locations

16. Introduced new products and services

17. Opened the same business elsewhere

18. Sell equity in the business

19. Cultural change

The summary statistics show that the average number of organizations implementing each of these changes is 30 , which is $39 \%$ of the respondent organizations. The most frequently occurring change is in management personnel (number 5) because frequently a change in management brings about other flow-on changes. Systems changes (number 9) and change in job roles of employees (number 11) are reported as the next most frequentlymade changes. The lowest level of change occurred in selling equity (number 18), followed by cultural changes (number 19) and opening the same business elsewhere (number 17).

A graphical frequency distribution is shown in Figure 2. The horizontal axis denotes each change from 1 to 19; the vertical axis denotes the number of organizations making each change occur. 


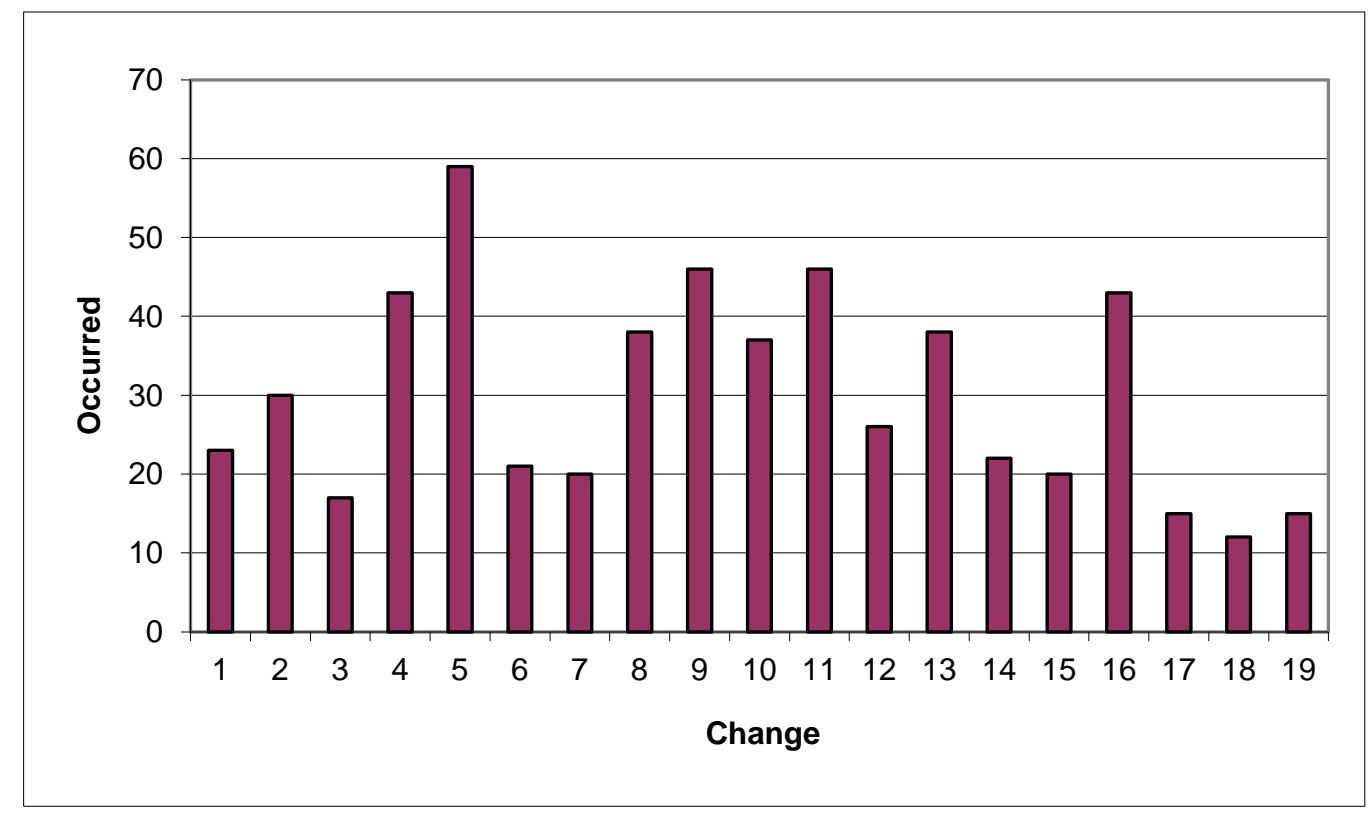

Figure 2 - Frequency Distribution of Organizational Changes Implemented

Since these 19 changes are difficult to quantify in terms of the importance of each change in relation to achieving organizational change, an equal weight is assigned to each change and calculations are undertaken to determine whether any relationship exists between the implementation of organizational changes and financial performance. First, the numbers of changes implemented in each organization have been counted. Then we examine the relationship between the number of changes implemented and the level of financial performance (the profit or loss level). This is accomplished by calculating the correlation coefficient between these two variables. The result shows a coefficient of -0.07643 , which is statistically insignificant.

Again, the result should not be a surprise for at least two reasons. Firstly, the purpose for implementing these changes in an organization is not solely for the improvement of financial performance. A good example is cultural change (number 19). Secondly, implementing these changes requires a significant investment in the short or intermediate term; and the positive effects of the changes implemented in an organization will take time to be reflected in the financial results. Examples are major change in product or service (number 1), reorganization of management structure (number 4), major new plant, equipment or technology (number 6), and there are others.

Question Three: Please indicate which of the following objectives you have achieved in introducing organizational change in your organization in the past 3 years.

1. Reduced labour costs

2. Improved labour productivity

3. Increased competitiveness

4. Improved labour flexibility

5. Improved decision-making

6. Improved services to customers/clients

7. Improved internal communications

8. Increased employee consultation

9. Increased employee commitment

10. Lower absenteeism rates

11. Reduced operational costs/expenses

12. Waste reductions

13. Improved business processes

14. Significant market revenue opportunity 
15. Improved quality of products/services

16. Increase of market share

17. Meet strategic plan objectives

18. Decrease threat to survival

19. Cultural change

A graphical frequency distribution is shown in Figure 3. The horizontal axis denotes each objective from 1 to 19 ; the vertical axis denotes the number of organizations having achieved each objective.

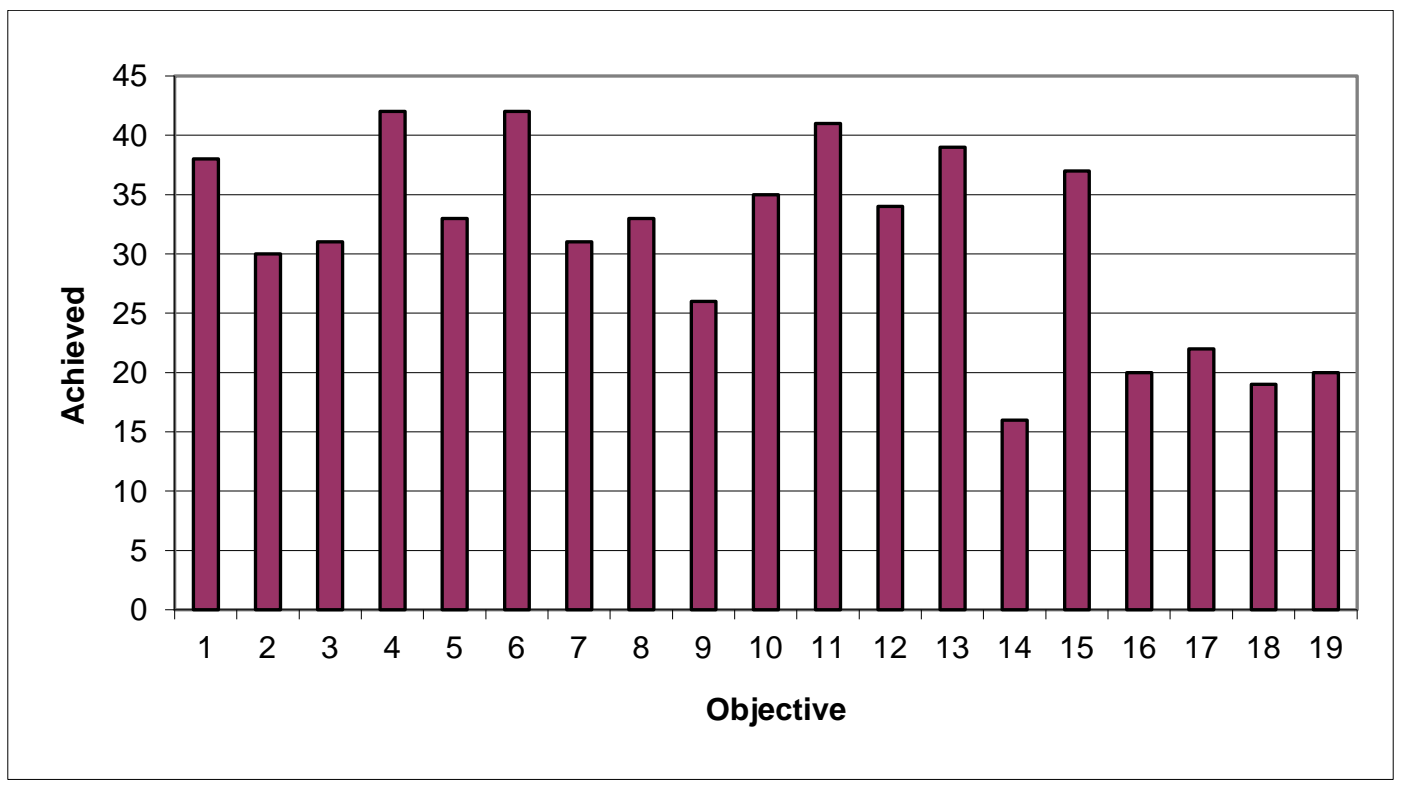

Figure 3 - Frequency distribution of Organizational Change Objectives

The summary statistics show that the average number of organizations achieving the objectives of a change process is 31 , which represents $40 \%$ of all surveyed organizations. The most achieved objective is improved labour flexibility (number 4), followed by improved services to customers/clients (number 6), and reduced operational costs/expenses (number 11). The least achieved objective is pursuit of a significant market revenue opportunity (number 14), followed by decreasing a threat to survival (number 18), and achieving cultural change (number 19).

These 19 objectives are also difficult to quantify in terms of the importance of each objective to successful organizational change. For simplicity and practicality, an equal weight is assigned to each objective. First, the numbers of the objectives achieved by each organization have been counted. Then we examine the relationship between the number of objectives achieved and the level of financial performance (the profit or loss level) By computing the correlation coefficient between these two variables. The result shows a coefficient of 0.1539 , which indicates a weak positive correlation between the two variables.

Unlike the previous two questions, most objectives listed in this question, such as improved labour productivity, lower absenteeism rates, are directly connected to labour costs and are related to financial performance of an organization. Furthermore, achieving these objectives can result in immediate financial gains. Examples are reduced operational costs/expenses and waste reduction. However, some objectives, such as increased employee consultation and increased employee commitment, are not designed for the sole purpose of improving financial performance; or achieving these objectives requires a significant financial commitment in the short or intermediate term, but has the potential to pay off financially in the longer term.

Finally, an interesting finding is that the average percentages of all respondent organizations applying change practices, experiencing organizational changes, and achieving objectives are almost the same at approximately $40 \%$ of the SMEs responding. These results show that there is a consistency among these three measures of organizational change. The individual percentages are shown in Table 5. 
Table 5 - Percentage of SMEs applying change practices, implementing changes and achieving change management objectives $\%$ applying change practices $\%$ experiencing changes \% achieving objectives $38.9 \%$ $39.0 \%$ $40.3 \%$

\section{LIMITATIONS}

While concerted effort was made to gather the appropriate number of responses to provide a statistically significant sample, "survey fatigue" is prevalent and after repeated attempts to encourage participation, currency of the responses became an increasingly important concern. The lack of a satisfactory statistical sample size limits the generalizability to the population of SMEs as a whole.

While the surveys were all directed to management within each organization, a further limitation arises from any self-reporting bias.

\section{CONCLUSIONS}

SMEs were asked to consider 37 separately identified organizational change practices and indicate whether or not they were engaged in these practices. Results show that SMEs are engaged to some degree in all of these changes but their greatest emphasis has been focused on implementing organizational change practices to enhance the flexibility of their work force. While work force flexibility is important to surviving market and seasonal fluctuations in demand, a concern arises in relation to the attainment of the expectation of these organizations as creators of employment opportunities. There is a moderate level of engagement in practices that improve conditions of employment and encourage employee retention. There is wide engagement by SMEs in organizational change practices and those being implemented are to a large extent driven by the motivation to improve flexibility in the work force.

SMEs are experiencing significant levels of organizational change with changes in management being the most frequently reported change. Almost $40 \%$ of SMEs report that the objectives pursued in implementing changes are achieved. While substantial improvement could be made in relation to the achievement of objectives, approximately $80 \%$ of the respondent SMEs have been operating for more than five years. SMEs also report reasonable levels of success in attaining the objectives pursued with organizational change. The most significant are improved labour flexibility, improved levels of customer service and better cost control.

In response to RQ4, there is no significant relationship between financial performance of SMEs and the numbers of organizational change practices or in the changes which have taken place in the past three years. The existence of a positive, albeit weak, correlation between the achievement of the objectives of organizational change and financial performance is congruent with the concept that the flexibility of SMEs is an essential characteristic for survival and growth in changing economic environments.

The flexibility and survivability of these firms augurs well for the sector and will assist them in meeting the expectations for economic participation in relation to the provision of investment opportunities and employment creation.

\section{AUTHOR INFORMATION}

Heather Banham earned her Doctor of Business Administration degree at the University of Southern Queensland, Australia and holds her professional accounting designation as a CGA (Certified General Accountant) in Canada and CPA in Australia. She is currently serving as Dean in the Okanagan School of Business at Okanagan College and her research interests include organizational change, international education and small and medium enterprises. E-mail: hbanham@okanagan.bc.ca (Corresponding author)

Yunke He received his Ph.D. degree from McMaster University in Canada and is a CFA charter holder. He teaches at the Okanagan School of Business and has published in academic journals including American Journal of Business 
Education, International Business \& Economics Research Journal, Journal of International Business and Economics, Journal of Investment Economics, and Journal of Quantitative Economics. E-mail: yhe@okanagan.bc.ca

\section{REFERENCES}

1. Banham, H.C. (2005). Organizational Change in SMEs - A Regional Study. Retrieved from: http://eprints.usq.edu.au/view/people/Banham=3AHeather_C $=2 \mathrm{E}=3 \mathrm{~A}=3 \mathrm{~A} . \mathrm{html}$

2. Bell, J., \& Loane, S. (2010). 'New-wave' global firms: Web 2.0 and SME internationalisation. Journal of Marketing Management, 26(3/4), 213-229. doi:10.1080/02672571003594648

3. Bumgardner, M., Buehlmann, U., Schuler, A., \& Crissey, J. (2011).Competitive Actions of Small Firms in a Declining Market. Journal of Small Business Management, 49(4), 578-598. doi:10.1111/j.1540627X.2011.00337.X

4. By, R., \& Dale, C. (2008). The successful management of organisational change in tourism SMEs: initial findings in UK visitor attractions. International Journal of Tourism Research, 10(4), 305-313.

5. Cunningham, L. (2010). Managing human resources in SMEs in a transition economy: evidence from China. International Journal of Human Resource Management, 21(12), 2120-2141. doi:10.1080/09585192.2010.509620

6. Done, A., Voss, C. \& Rytter, N.G. (2011). Best practice interventions: Short-term impact and long-term outcomes. Journal of Operations Management, 29 (Special Issue on Field Research in Operations and Supply Chain Management), 500-513. doi:10.1016/j.jom.2010.11.007

7. Prater, E. \& Ghosh, S, (2006). A comparative model of firm size and the global operational dynamics of US firms in Europe. Journal of Operations Management, 24 (5), 511-529. 